\title{
Controle integrado da ferrugem asiática da soja (Phakopsora pachyrhizi) com o fungicida fluquinconazole aplicado nas sementes em associação com outros fungicidas pulverizados na parte aérea da cultura
}

\author{
Augusto César Pereira Goulart ${ }^{1}$, Silvânia Helena Furlan², Marco Tadao Fujino ${ }^{3}$
}

${ }^{1}$ Embrapa Agropecuária Oeste, Cx. Postal 661, CEP: 79804-970, Dourados, MS; ${ }^{2}$ Instituto Biológico, Cx. Postal 70, CEP: 13.001-970 Campinas, SP., ${ }^{3}$ Bayer CropScience; Dourados, MS.

Autor para correspondência: Augusto César Pereira Goulart (goulart@cpao.embrapa.br)

Data de chegada: 22/11/2009. Aceito para publicação em: 15/10/2010.

\section{RESUMO}

1654

Goulart, A.C.P.; Furlan, S.H.; Fujino, M.T. Controle integrado da ferrugem asiática da soja (Phakopsora pachyrhisi) com o fungicida fluquinconazole aplicado nas sementes em associação com outros fungicidas pulverizados na parte aérea da cultura. Summa Phytopathologica, v.37, n.2, p.113-118, 2011.

O objetivo deste trabalho foi avaliar o controle da ferrugem asiática da soja (Phakopsora pachyrhizi) pela integração do tratamento de sementes com o fungicida fluquinconazole e a pulverização de fungicidas na parte aérea da cultura. Dois ensaios foram instalados na safra 2006/07, um em Dourados, MS, usando sementes de soja da cv. BRS 245 RR e o outro em Paulínia, SP com a cv. CD 208. Foram avaliados a severidade da doença, a desfolha e o rendimento de grãos. O delineamento experimental usado foi o de blocos ao acaso, com quatro repetições, em arranjo fatorial $2 \times 5$, com dois tratamentos de semente, com e sem fluquinconazole, e cinco combinações de misturas de fungicidas aplicadas na parte aérea da soja. Os resultados observados nestes ensaios mostraram que a adição do fluquinconazole ao tratamento de sementes padrão na cultura da soja, sem considerar a aplicação de fungicidas na parte aérea da cultura, atrasou a evolução

da ferrugem da soja, apresentando diferença significativa com o tratamento de sementes padrão sem o fluquinconazole, em relação à severidade e desfolha, o que não ocorreu com relação ao rendimento de grãos. Considerando a integração entre o tratamento de sementes com fluquinconazole e os fungicidas aplicados na parte aérea da soja, na maioria das avaliações de severidade da ferrugem e de desfolha, bem como em relação ao rendimento de grãos da cultura, não foi observada interação significativa entre estas duas práticas. As aplicações foliares de fungicidas foram eficientes para o controle da ferrugem da soja, proporcionando menores níveis de severidade e de desfolha, o que refletiu de forma positiva no rendimento de grãos da cultura, em comparação com a testemunha não tratada. Não foram observados efeitos fitotóxicos nas plantas de soja decorrentes da utilização do fungicida fluquinconazole nas sementes.

Palavras-chave adicionais: rendimento de grãos, desfolha, tratamento de sementes.

ABSTRACT

Goulart, A.C.P.; Furlan, S.H.; Fujino, M.T. Integrated control of soybean rust (Phakopsora pachyrhizi) using the fungicide fluquinconazole applied as seed dressing associated with other fungicides spraying on soybean above ground parts. Summa Phytopathologica, v.37, n.2, p.113-118, 2011.

The objective of this work was to evaluate the control of soybean rust (Phakopsora pachyrhizi) using seed dressing with fluquinconazole integrated with fungicides spraying in soybean above ground parts. Two experiments were carried out, in the crop season 2006/07, at Dourados, MS and Paulinia, SP, using soybean seeds of the cultivars BRS 245 RR and CD 208, respectively. Soybean rust severity, defoliation and yield were evaluated in this experiment. The experimental design was a randomized complete block, with four replications, using a factorial arrangement of $2 \times 5$ with two treatments of seeds, with and without fluquinconazole, and five combinations of foliar fungicide mixtures applications. The results observed in these experiments showed that the addition of fluquinconazole to standard seed treatment in soybeans, without considering the foliar fungicides application, delayed the soybean rust progress, and showed significant difference from standard seed treatment without fluquinconazole in relation to disease severity and defoliation, but not for grain yield. Considering the integration of seed treatment with fluquinconazol and foliar fungicides application, in the majority of the evaluations of rust severity and defoliation, as well as in relation to grain yield, no significant interaction between these two practices was observed. The foliar fungicides application were effective in the control of soybean rust, providing lower levels of disease severity and defoliation and higher grain yield, in relation to untreated control. No phytotoxic effects on soybean plants due to use of fluquinconazole on soybean seeds were observed.

Keywords: yield, defoliation, seed treatment

Uma das doenças de maior importância no hemisfério oriental do planeta, devido à alta virulência com que incide, é a ferrugem asiática da soja, causada pelo fungo Phakopsora pachyrhizi Syd. \& P.Syd. Trata-se da principal doença dessa cultura em áreas tropicais e subtropicais (3). Perdas de até $40 \%$ têm sido relatadas no Japão; de
$10 \%$ a $50 \%$, no Sul da China; $10 \%$ a $40 \%$, na Tailândia e de $23 \%$ a $90 \%$ em Taiwan. Perdas quase totais podem ocorrer em determinadas áreas, na maioria desses países (17). No Brasil, esta doença foi detectada em 2001 (21), e desde a safra agrícola de 2003/2004, tem sido constatada em todas as regiões produtoras de soja no Brasil, exceto em Roraima 
(20). As perdas causadas na produção de soja brasileira, até a safra 2006/2007, são da ordem de 14 milhões de toneladas de grãos (4).

A ferrugem da soja pode ser eficientemente controlada com fungicidas dos grupos dos triazóis e das estrobilurinas e suas misturas, desde que as pulverizações sejam realizadas no início da infecção (1). A obtenção de cultivares resistentes tem sido dificultada em função da existência de raças do fungo. Até o momento, não há cultivares resistentes a essa doença (18).

Com o advento dos fungicidas sistêmicos, principalmente aqueles pertencentes ao grupo dos triazóis, abre-se uma possibilidade viável de controle dessa enfermidade via semente na cultura da soja, pelo fato de esses produtos possuírem características de penetração, translocação e efeito residual prolongado nas plântulas, conforme evidencia Azevedo (2). Esse tipo de prática visa não só o controle de patógenos da semente como também da parte aérea que atacam a cultura nos estádios iniciais de desenvolvimento. Segundo Martinelli (13), o tratamento de sementes com fungicidas pode promover benefícios adicionais no controle de doenças, quando integrado ao tratamento químico da parte aérea, permitindo, dessa forma, o seu uso nos programas de manejo integrado de doenças. Conforme Menegon et al. (14), a interação do tratamento de sementes e de parte aérea tem sido analisada relacionando alguns componentes da epidemia, tais como o tempo para aparecimento da doença, sua intensidade inicial, taxa de progresso e quantidade final.

Trabalhos de pesquisa têm demonstrado que a adoção integrada do tratamento de sementes com fungicidas com a pulverização convencional da parte aérea da soja visando o controle da ferrugem asiática tem proporcionado a obtenção de uma lavoura com menor incidência da doença, resultante da redução na velocidade de aumento desta enfermidade ou do atraso no seu aparecimento, ou por ambos os fatores. Como conseqüência deste manejo, observa-se, no final do ciclo da cultura, plantas com melhor aspecto do ponto de vista sanitário (6).

O tratamento de sementes de soja com fungicidas, do ponto de vista de manejo integrado de doenças, é um dos métodos mais simples, de custo baixo e resulta em reflexos altamente positivos para o aumento da produtividade da cultura, representando apenas $0,6 \%$ do custo de produção/ha, conforme Goulart \& Melo Filho (9) e Henning et al. (10).

Para o manejo da ferrugem asiática, o tratamento de sementes com o fluquinconazole é recente - passou a ser recomendado em 2007 - e vem sendo adotado em diferentes regiões produtoras de soja no país (18). As vantagens do seu uso foram relatadas em poucos trabalhos $(5,15)$, mas sabe-se que pode trazer benefícios ao produtor quando associado a outras práticas de controle, por afetar componentes da epidemia, sobretudo a taxa de progresso da doença. O seu uso nas sementes de soja associado com aplicações foliares de fungicidas, contribui para maximizar o controle da ferrugem asiática da soja, em comparação aos resultados obtidos sem o tratamento das sementes com o referido fungicida. Neste contexto, deve-se ressaltar que, até o momento, somente o fungicida sistêmico fluquinconazole, pertencente ao grupo químico dos triazóis, tem registro para esse fim, o qual não substitui o tratamento químico convencional/padrão das sementes de soja (o qual deve ser realizado com fungicidas sistêmicos e de contato), visando o controle de fungos das sementes e eventualmente de alguns presentes no solo. Desta forma, a recomendação da adição do fungicida fluquinconazole ao tratamento de sementes padrão visa somente retardar a evolução da ferrugem da soja na parte aérea das plantas (18). Resultados de pesquisa $(5,11,1215,16,19)$ demonstraram que a utilização do fluquinconazole não ocasiona problemas de fitotoxicidade à soja como pode ocorrer com outros fungicidas triazóis já estudados.

O objetivo deste trabalho foi avaliar o controle da ferrugem asiática da soja (Phakopsora pachyrhizi) pela integração do tratamento de sementes com o fungicida fluquinconazole e a pulverização de fungicidas na parte aérea da cultura.

\section{MATERIAL E MÉTODOS}

Dois ensaios foram instalados a campo, na safra 2006/07, um em Paulínia, SP no dia 20 de outubro de 2006 e o outro em Dourados, MS no dia 13 de dezembro de 2006. Foram utilizadas sementes de soja da cv. CD 208 e cv. BRS 245 RR, respectivamente. No mesmo dia em que as sementes foram tratadas com os fungicidas, os ensaios foram instalados. Em ambos os ensaios, a emergência das plântulas ocorreu 7 dias após a semeadura.

O seguinte procedimento foi usado para o tratamento: $500 \mathrm{~g} \mathrm{de}$ sementes de soja para cada tratamento foram colocadas em sacos plásticos de 2,0 litros, onde adicionaram-se os fungicidas e os inseticidas, agitando-se o recipiente até a completa cobertura das sementes pelos produtos.

Os dois experimentos foram instalados em parcelas de $14,4 \mathrm{~m}^{2}$ $(2,4 \mathrm{~m} \times 6 \mathrm{~m})$. Foram consideradas como bordadura as duas fileiras laterais e $0,50 \mathrm{~m}$ em cada extremidade da parcela. A adubação foi realizada por ocasião da semeadura, utilizando-se $300 \mathrm{~kg} / \mathrm{ha}$ da fórmula 4-30-10 (N-P-K). A densidade de semeadura foi de 20 sementes/metro. Todas as sementes foram tratadas com carbendazim + thiram + imidacloprid (30+70+60 g do i.a. por $100 \mathrm{~kg}$ de sementes), conforme o padrão de tratamento, sendo que depois a metade foi tratada com o fluquinconazole, na dose de $50 \mathrm{~g}$ do i.a. por $100 \mathrm{~kg}$ de sementes. A pulverização dos fungicidas foi realizada utilizando pulverizador costal de pressão constante $\left(\mathrm{CO}_{2}\right)$, volume de pulverização de $200 \mathrm{~L} / \mathrm{ha}$; pressão de operação de $3 \mathrm{BAR}$; tipo de bico duplo-leque com ângulo de abertura 110.015; espaçamento entre bicos de $40 \mathrm{~cm}$ e largura da barra de 2,4 m. Foram realizadas quatro avaliações de severidade (área foliar coberta com sintomas) da ferrugem (em cada avaliação foram amostrados os terços inferior, médio e superior das plantas, avaliando 10 folhas para cada terço amostrado, em três pontos de cada parcela) conforme escala diagramática proposta por Godoy et al. (7), duas avaliações de desfolha, duas avaliações de fitotoxicidade (em 12 e 22 de março de 2007 para o ensaio realizado em Dourados) e avaliado também o rendimento de grãos de cada parcela em $\mathrm{kg} / \mathrm{ha}$, a $13 \%$ de unidade.

Os tratamentos e doses aplicados na parte aérea das plantas nos dois ensaios foram: pyraclostrobin + epoxiconazole $(66,5+25 \mathrm{~g}$ do i.a./ha), trifloxystrobin + ciproconazole + Aureo $(56,2+24 \mathrm{~g}$ do i.a./ha $+0,25 \%)$, azoxystrobin + ciproconazole + Nimbus $(60+24 \mathrm{~g}$ do i.a. $/ \mathrm{ha}+600 \mathrm{ml} / \mathrm{ha})$; pyraclostrobin + propiconazole + Áureo + tebuconazole $(50+100 \mathrm{~g}$ do i.a./ha $+0,5 \%+100 \mathrm{~g}$ do i.a./ha). Foram realizadas três aplicações dos fungicidas, conforme o cronograma a seguir.

\section{Cronograma das pulverizações}

Dourados, MS

\begin{tabular}{ccc}
\hline $\begin{array}{c}\text { Início do } \\
\text { florescimento }-\mathrm{R} 1\end{array}$ & $\begin{array}{c}\text { Formação de } \\
\text { vagens }-\mathrm{R} 4\end{array}$ & $\begin{array}{c}\text { Enchimento de } \\
\text { grãos }-\mathrm{R} 5.2\end{array}$ \\
\hline 0,1\% de severidade & $5 \%$ de severidade & $30 \%$ de severidade \\
de ferrugem no & de ferrugem no & de ferrugem no \\
Tratamento & Tratamento & Tratamento \\
Testemunha & Testemunha & Testemunha \\
\hline
\end{tabular}


Paulínia,SP

\begin{tabular}{ccc}
\hline $\begin{array}{c}\text { Início do } \\
\text { florescimento }-\mathrm{R} 1\end{array}$ & $\begin{array}{c}\text { Formação de } \\
\text { vagens }-\mathrm{R} 4\end{array}$ & $\begin{array}{c}\text { Enchimento de } \\
\text { grãos }-\mathrm{R} 5.2\end{array}$ \\
\hline 0,0\% de severidade & $0,65 \%$ de severidade & $61,3 \%$ de severidade \\
de ferrugem no & de ferrugem no & de ferrugem no \\
Tratamento & Tratamento & Tratamento \\
Testemunha & Testemunha & Testemunha \\
\hline
\end{tabular}

O delineamento estatístico usado foi o de blocos ao acaso com quatro repetições, em esquema fatorial $2 \times 5$, com dois tratamentos de sementes e cinco tratamentos da parte aérea. Os dados de percentagem foram transformados para arc sen $\sqrt{\mathrm{x} / 100}$ e submetidos à análise de variância. As médias foram comparadas pelo teste de Duncan, ao nível de $5 \%$ de probabilidade, com o ASSISTAT.

\section{RESULTADOS E DISCUSSÃO}

Nas Tabelas 1 a 4 encontram-se os resultados obtidos nos ensaios realizados em Dourados, MS e em Paulínia, SP.

Foi observado efeito significativo da interação entre o tratamento de sementes com fluquinconazole e os fungicidas aplicados na parte aérea da soja, quanto à severidade da ferrugem e desfolha. Entretanto, não houve resposta significativa desta interação quanto ao rendimento de grãos.

Com relação à severidade da ferrugem da soja (Tabelas 1 e 2), resultados semelhantes foram encontrados para os dois ensaios (Dourados e Paulinia). Considerando apenas o tratamento das sementes, com e sem o fluquinconazole (tratamento testemunha), sem levar em conta as aplicações de fungicidas na pare aérea da soja, menores percentagens de área foliar coberta com sintomas da ferrugem foram observadas nas parcelas onde o fluquinconazole foi aplicado nas sementes, considerando os dois locais dos ensaios e as quatro avaliações realizadas. Até os 103 DAP não foi observado efeito significativo da interação entre o tratamento de sementes com fluquinconazole e os fungicidas aplicados na parte aérea da soja, o qual foi observado apenas na $4^{\mathrm{a}}$ avaliação, para os tratamentos pyraclostrobin + epoxiconazole $(66,5+25 \mathrm{~g}$ do i.a./ha) e trifloxystrobin + ciproconazole + Aureo (56,2 $+24 \mathrm{~g}$ do i.a./ha $+0,25 \%$ ), tanto para o ensaio conduzido em Dourados, MS, quanto para o de Paulínia, SP. Para os tratamentos azoxystrobin + ciproconazole + Nimbus $(60+24 \mathrm{~g}$ do i.a. $/ \mathrm{ha}+600 \mathrm{ml} / \mathrm{ha})$ e pyraclostrobin + propiconazole + Áureo + tebuconazole $(50+100 \mathrm{~g}$ do i.a./ha $+0,5 \%+100 \mathrm{~g}$ do i.a./ha) nas quatro épocas de avaliações, esta interação não foi significativa, o que demonstra não haver efeito positivo da integração do tratamento de sementes com fluquinconazole e a pulverização desses fungicidas na parte aérea da soja, visando o controle da ferrugem. Todos os fungicidas aplicados na parte aérea foram estatisticamente superiores à testemunha sem tratamento, apresentando menores índices de severidade da ferrugem da soja, confirmando a eficiência desta prática de manejo no controle dessa doença, o qual se apresentou neste trabalho acima de $80 \%$.

Considerando as avaliações de desfolha realizadas nos dois ensaios (Tabela 3), de uma maneira geral, foi observado efeito significativo da interação entre o tratamento de sementes com fluquinconazole e os fungicidas aplicados na parte aérea da soja, onde diferenças estatísticas entre alguns tratamentos avaliados foram observadas. Da mesma forma, levando em conta apenas o tratamento das sementes, com e sem o fluquinconazole (tratamento testemunha), sem considerar as aplicações de fungicidas na pare aérea da soja, menores percentagens de desfolha foram observadas nas parcelas onde o fluquinconazole foi aplicado nas sementes, para as duas avaliações realizadas no ensaio de Dourados e apenas para a primeira avaliação realizada em Paulinia. Considerando agora a integração do tratamento de sementes com a aplicação dos fungicidas na parte aérea, observou-se efeito positivo desta prática nas duas avaliações realizadas no ensaio de Dourados, para todos os tratamentos fungicidas aplicados na parte aérea. No caso do experimento instalado em Paulinia, apenas para os tratamentos pyraclostrobin + epoxiconazole $(66,5+25 \mathrm{~g}$ do i.a./ha) e trifloxystrobin + ciproconazole + Aureo (56,2 + 24g do i.a./ha + 0,25\%), na segunda avaliação de desfolha, observou-se efeito significativo desta interação. Igualmente ao ocorrido com relação às avaliações de severidade, todos os fungicidas aplicados na parte aérea foram estatisticamente superiores

Tabela 1. Severidade da ferrugem asiática da soja em função dos tratamentos fungicidas aplicados no ensaio de Dourados, MS

\begin{tabular}{|c|c|c|c|c|c|c|c|c|c|c|c|c|c|c|c|c|}
\hline \multirow{3}{*}{$\begin{array}{l}\text { Tratamentos } \\
\text { 1. Testemunha }\end{array}$} & \multicolumn{4}{|c|}{$\begin{array}{c}1^{\text {a }} \text { Avaliação }(\%) \\
93 \text { DAP } \\
12 / 03 / 07 \\
\end{array}$} & \multicolumn{4}{|c|}{$\begin{array}{c}2^{a} \text { Avaliação }(\%) \\
97 \text { DAP } \\
16 / 03 / 07\end{array}$} & \multicolumn{4}{|c|}{$\begin{array}{c}3^{\text {a }} \text { Avaliação }(\%) \\
103 \text { DAP } \\
22 / 03 / 07\end{array}$} & \multicolumn{4}{|c|}{$\begin{array}{c}4^{a} \text { Avaliação }(\%) \\
109 \text { DAP } \\
28 / 03 / 07\end{array}$} \\
\hline & \multicolumn{2}{|c|}{$\begin{array}{l}\text { TS padrão sem } \\
\text { fluquinconazole }\end{array}$} & \multicolumn{2}{|c|}{$\begin{array}{l}\text { TS padrão com } \\
\text { fluquinconazole }\end{array}$} & \multicolumn{2}{|c|}{$\begin{array}{l}\text { TS padrão sem } \\
\text { fluquinconazole }\end{array}$} & \multicolumn{2}{|c|}{$\begin{array}{l}\text { TS padrão com } \\
\text { fluquinconazole }\end{array}$} & \multicolumn{2}{|c|}{$\begin{array}{l}\text { TS padrão sem } \\
\text { fluquinconazole }\end{array}$} & \multicolumn{2}{|c|}{$\begin{array}{l}\text { TS padrão com } \\
\text { fluquinconazole }\end{array}$} & \multicolumn{2}{|c|}{$\begin{array}{l}\text { TS padrão sem } \\
\text { fluquinconazole }\end{array}$} & \multicolumn{2}{|c|}{$\begin{array}{l}\text { TS padrão com } \\
\text { fluquinconazole }\end{array}$} \\
\hline & $30 \mathrm{a}$ & A & $20 \mathrm{a}$ & B & $40 \mathrm{a}$ & A & $30 \mathrm{a}$ & B & $70 \mathrm{a}$ & A & $57 \mathrm{a}$ & B & $90 \mathrm{a}$ & A & $63 \mathrm{a}$ & B \\
\hline $\begin{array}{l}\text { 2. Pyraclostrobin } \\
+ \text { epoxiconazole } \\
\end{array}$ & $5 \mathrm{~b}$ & A & $4 \mathrm{~b}$ & A & $5 \mathrm{~b}$ & A & $4 \mathrm{~b}$ & A & $11 \mathrm{~b}$ & A & $10 \mathrm{~b}$ & A & $29 \mathrm{~b}$ & A & $18 \mathrm{~b}$ & B \\
\hline $\begin{array}{l}\text { 3. Trifloxystrobin } \\
+ \text { ciproconazole }+ \text { Aureo }\end{array}$ & $3 \mathrm{~b}$ & A & $1 \mathrm{~b}$ & A & $3 \mathrm{~b}$ & A & $1 \mathrm{~b}$ & A & $11 \mathrm{~b}$ & A & $9 \mathrm{~b}$ & A & $24 \mathrm{~b}$ & A & $16 \mathrm{~b}$ & B \\
\hline $\begin{array}{l}\text { 4. Azoxystrobin }+ \\
\text { ciproconazole }+ \text { Nimbus }\end{array}$ & $2 \mathrm{~b}$ & A & $2 \mathrm{~b}$ & A & $2 b$ & A & $2 \mathrm{~b}$ & A & $9 \mathrm{~b}$ & A & $5 \mathrm{c}$ & A & $19 c$ & A & $14 \mathrm{~b}$ & A \\
\hline $\begin{array}{l}\text { 5. Pyraclostrobin } \\
+ \text { propiconazole }+ \text { Áureo) } \\
+ \text { tebuconazole }\end{array}$ & $2 b$ & $\mathrm{~A}$ & $1 \mathrm{~b}$ & A & $2 b$ & $\mathrm{~A}$ & $1 \mathrm{~b}$ & A & $6 \mathrm{~b}$ & A & $4 \mathrm{c}$ & A & $19 \mathrm{c}$ & A & $14 \mathrm{~b}$ & $\mathrm{~A}$ \\
\hline
\end{tabular}

Médias seguidas de mesma letra minúscula na coluna e maiúscula na linha não diferem significativamente entre si (Duncan, 5\%)

C.V. $(\%)=18,8$

DAP = dias após o plantio

TS padrão $=$ tratamento de sementes padrão $=$ carbendazim + thiram + imidacloprid 
Tabela 2. Severidade da ferrugem da soja em função dos tratamentos fungicidas aplicados no ensaio de Paulínia, SP.

\begin{tabular}{|c|c|c|c|c|c|c|c|c|c|c|c|c|c|c|c|c|}
\hline \multirow{3}{*}{$\begin{array}{l}\text { Tratamentos } \\
\text { 1. Testemunha }\end{array}$} & \multicolumn{4}{|c|}{$\begin{array}{c}1^{\mathrm{a}} \text { Avaliação }(\%) \\
84 \text { DAP } \\
12 / 01 / 07\end{array}$} & \multicolumn{4}{|c|}{$\begin{array}{c}2^{a} \text { Avaliação }(\%) \\
88 \text { DAP } \\
16 / 01 / 07\end{array}$} & \multicolumn{4}{|c|}{$\begin{array}{c}3^{\mathrm{a}} \text { Avaliação }(\%) \\
95 \text { DAP } \\
23 / 01 / 07\end{array}$} & \multicolumn{4}{|c|}{$\begin{array}{c}4^{\mathrm{a}} \text { Avaliação }(\%) \\
103 \text { DAP } \\
31 / 01 / 07\end{array}$} \\
\hline & \multicolumn{2}{|c|}{$\begin{array}{l}\text { TS padrão sem } \\
\text { fluquinconazole }\end{array}$} & \multicolumn{2}{|c|}{$\begin{array}{l}\text { TS padrão com } \\
\text { fluquinconazole }\end{array}$} & \multicolumn{2}{|c|}{$\begin{array}{c}\text { TS padrão sem } \\
\text { fluquinconazole }\end{array}$} & \multicolumn{2}{|c|}{$\begin{array}{l}\text { TS padrão com } \\
\text { fluquinconazole }\end{array}$} & \multicolumn{2}{|c|}{$\begin{array}{c}\text { TS padrão sem } \\
\text { fluquinconazole }\end{array}$} & \multicolumn{2}{|c|}{$\begin{array}{l}\text { TS padrão com } \\
\text { fluquinconazole }\end{array}$} & \multicolumn{2}{|c|}{$\begin{array}{l}\text { TS padrão sem } \\
\text { fluquinconazole }\end{array}$} & \multicolumn{2}{|c|}{$\begin{array}{l}\text { TS padrão com } \\
\text { fluquinconazole }\end{array}$} \\
\hline & $14 \mathrm{a}$ & A & $0 \mathrm{a}$ & B & $26 \mathrm{a}$ & A & $20 \mathrm{a}$ & B & $67 \mathrm{a}$ & A & $60 \mathrm{a}$ & B & $84 \mathrm{a}$ & A & $68 \mathrm{a}$ & B \\
\hline $\begin{array}{l}\text { 2.Pyraclostrobin + } \\
\text { epoxiconazole }\end{array}$ & $0 \mathrm{~b}$ & A & $0 \mathrm{a}$ & A & $3 \mathrm{~b}$ & A & $1 \mathrm{~b}$ & A & $6 \mathrm{~b}$ & A & $5 \mathrm{~b}$ & A & $14 \mathrm{~b}$ & A & $9 \mathrm{~b}$ & B \\
\hline $\begin{array}{l}\text { 3. Trifloxystrobin }+ \\
\text { ciproconazole }+ \text { Aureo }\end{array}$ & $0 \mathrm{~b}$ & A & $0 \mathrm{a}$ & A & $2 \mathrm{~b}$ & A & $1 \mathrm{~b}$ & A & $7 \mathrm{~b}$ & A & $5 \mathrm{~b}$ & A & $13 \mathrm{~b}$ & A & $8 \mathrm{~b}$ & B \\
\hline $\begin{array}{l}\text { 4. Azoxystrobin }+ \\
\text { ciproconazole }+ \text { Nimbus }\end{array}$ & $0 \mathrm{~b}$ & A & $0 \mathrm{a}$ & A & $2 \mathrm{~b}$ & A & $0 \mathrm{~b}$ & A & $5 \mathrm{~b}$ & A & $3 \mathrm{~b}$ & A & $8 \mathrm{c}$ & A & $5 \mathrm{~b}$ & A \\
\hline $\begin{array}{l}\text { 5. Pyraclostrobin }+ \\
\text { propiconazole }+ \text { Áureo) } \\
+ \text { tebuconazole }\end{array}$ & $0 \mathrm{~b}$ & A & $0 \mathrm{a}$ & A & $2 b$ & A & $0 \mathrm{~b}$ & A & $3 \mathrm{~b}$ & A & $2 \mathrm{~b}$ & A & $6 \mathrm{c}$ & A & $3 \mathrm{~b}$ & A \\
\hline
\end{tabular}

Médias seguidas de mesma letra minúscula na coluna e maiúscula na linha não diferem significativamente entre si (Duncan, 5\%)

C.V. $(\%)=20,2$

DAP = dias após o plantio

TS padrão $=$ tratamento de sementes padrão $=$ carbendazim + thiram + imidacloprid

Tabela 3. Desfolha devido à ferrugem da soja em função dos tratamentos fungicidas aplicados nos ensaios de Dourados, MS e Paulínia, SP.

\begin{tabular}{|c|c|c|c|c|c|c|c|c|c|c|c|c|c|c|c|}
\hline \multirow{3}{*}{$\begin{array}{l}\text { Tratamentos } \\
\text { 1. Testemunha }\end{array}$} & \multicolumn{3}{|c|}{$\begin{array}{c}\text { Desfolha }(\%) \\
1^{\mathrm{a}} \text { Avaliação } \\
\text { 28/03/07 - Dourados, MS }\end{array}$} & \multicolumn{4}{|c|}{$\begin{array}{c}\text { Desfolha }(\%) \\
2^{\text {a }} \text { Avaliação09/04/07 - } \\
\text { Dourados, MS }\end{array}$} & \multicolumn{4}{|c|}{$\begin{array}{c}\text { Desfolha }(\%) \\
1^{\text {a }} \text { Avaliação } \\
\text { 31/01/07 - Paulínia, SP }\end{array}$} & \multicolumn{4}{|c|}{$\begin{array}{c}\text { Desfolha }(\%) \\
2^{\text {a }} \text { Avaliação } \\
\text { 12/02/07 - Paulínia, SP }\end{array}$} \\
\hline & $\begin{array}{l}\text { TS padrão sem } \\
\text { fluquinconazole }\end{array}$ & \multicolumn{2}{|c|}{$\begin{array}{l}\text { TS padrão com } \\
\text { fluquinconazole }\end{array}$} & \multicolumn{2}{|c|}{$\begin{array}{l}\text { TS padrão sem } \\
\text { fluquinconazole }\end{array}$} & \multicolumn{2}{|c|}{$\begin{array}{l}\text { TS padrão com } \\
\text { fluquinconazole }\end{array}$} & \multicolumn{2}{|c|}{$\begin{array}{c}\text { TS padrão sem } \\
\text { fluquinconazole }\end{array}$} & \multicolumn{2}{|c|}{$\begin{array}{l}\text { TS padrão com } \\
\text { fluquinconazole }\end{array}$} & \multicolumn{2}{|c|}{$\begin{array}{l}\text { TS padrão sem } \\
\text { fluquinconazole }\end{array}$} & \multicolumn{2}{|c|}{$\begin{array}{l}\text { TS padrão com } \\
\text { fluquinconazole }\end{array}$} \\
\hline & $60 \mathrm{a}$ & $43 \mathrm{a}$ & B & $100 \mathrm{a}$ & A & $87 \mathrm{a}$ & B & $48 \mathrm{a}$ & A & $30 \mathrm{a}$ & B & $100 \mathrm{a}$ & A & $100 \mathrm{a}$ & A \\
\hline $\begin{array}{l}\text { 2.Pyraclostrobin }+ \\
\text { epoxiconazole }\end{array}$ & $15 \mathrm{~b}$ & $6 \mathrm{~b}$ & B & $90 \mathrm{~b}$ & A & $67 \mathrm{~b}$ & B & $5 \mathrm{~b}$ & A & $5 \mathrm{~b}$ & A & $24 \mathrm{~b}$ & A & $15 \mathrm{~b}$ & B \\
\hline $\begin{array}{l}\text { 3. Trifloxystrobin }+ \\
\text { ciproconazole }+ \text { Aureo }\end{array}$ & $15 \mathrm{~b}$ & $6 \mathrm{~b}$ & B & $88 \mathrm{~b}$ & A & $70 \mathrm{~b}$ & B & $5 \mathrm{~b}$ & A & $5 \mathrm{~b}$ & A & $21 \mathrm{~b}$ & A & $15 \mathrm{~b}$ & B \\
\hline $\begin{array}{l}\text { 4. Azoxystrobin }+ \\
\text { ciproconazole }+ \text { Nimbus }\end{array}$ & $10 \mathrm{~b}$ & $5 \mathrm{~b}$ & B & $83 \mathrm{~b}$ & A & $60 \mathrm{~b}$ & B & $5 \mathrm{~b}$ & A & $5 \mathrm{~b}$ & A & $15 \mathrm{~b}$ & A & $13 \mathrm{~b}$ & A \\
\hline $\begin{array}{l}\text { 5. Pyraclostrobin }+ \\
\text { propiconazole }+ \text { Áureo) } \\
+ \text { tebuconazole }\end{array}$ & $9 \mathrm{~b}$ & $5 \mathrm{~b}$ & B & $87 \mathrm{~b}$ & B & $60 \mathrm{~b}$ & B & $5 \mathrm{~b}$ & A & $5 \mathrm{~b}$ & A & $13 \mathrm{~b}$ & A & $12 \mathrm{~b}$ & A \\
\hline
\end{tabular}

Médias seguidas de mesma letra minúscula na coluna e maiúscula na linha não diferem significativamente entre si (Duncan, 5\%)

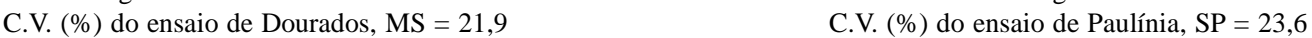

DAP = dias após o plantio

TS padrão $=$ tratamento de sementes padrão $=$ carbendazim + thiram + imidacloprid

à testemunha sem tratamento, apresentando menores índices de desfolha ocasionados pela incidência da ferrugem da soja.

Com relação ao rendimento de grãos (Tabela 4), não foi observada interação significativa entre o tratamento das sementes com fluquinconazole e os tratamentos de misturas de fungicidas aplicados na parte aérea da soja, evidenciando que, independente da presença ou não deste fungicida nas sementes de soja, o rendimento de grãos da cultura não foi influenciado. Entretanto, as melhores produtividades foram obtidas com a pulverização dos fungicidas na parte aérea da soja, independente da presença ou não do fluquinconazole nas sementes, refletindo em aumentos significativos no rendimento de grãos nos dois ensaios em relação à testemunha sem pulverização.

Não foram observados efeitos fitotóxicos nas plantas de soja decorrentes da utilização do fungicida fluquinconazole nas sementes.
Os resultados observados nestes ensaios mostraram que a adição do fluquinconazole ao tratamento de sementes padrão na cultura da soja, não considerando a aplicação de fungicidas na parte aérea da cultura, foi benéfica no sentido de atrasar a evolução da ferrugem da soja, apresentando diferença significativa com o tratamento de sementes padrão sem o fluquinconazole, em relação à severidade e desfolha, o que não ocorreu com relação ao rendimento de grãos. Considerando a integração entre o tratamento de sementes com fluquinconazole e os fungicidas aplicados na parte aérea da soja, na maioria das avaliações de severidade da ferrugem e de desfolha, bem como em relação ao rendimento de grãos da cultura, não foi observada interação significativa entre estas duas práticas. As aplicações foliares de fungicidas foram eficientes para o controle da ferrugem da soja, proporcionando menores níveis de severidade e de desfolha, o que refletiu de forma positiva no 
Tabela 4. Rendimento de grãos de soja em função dos tratamentos fungicidas aplicados nos ensaios de Dourados, MS e Paulínia, SP.

\begin{tabular}{|c|c|c|c|c|c|c|c|c|}
\hline \multirow{3}{*}{$\begin{array}{l}\text { Tratamentos } \\
\text { 1. Testemunha }\end{array}$} & \multicolumn{4}{|c|}{$\begin{array}{c}\text { Rendimento de grãos (Kg/ha) } \\
\text { Dourados, MS }\end{array}$} & \multicolumn{4}{|c|}{$\begin{array}{c}\text { Rendimento de grãos (Kg/ha) } \\
\text { Paulínia, SP }\end{array}$} \\
\hline & \multicolumn{2}{|c|}{ TS padrão sem fluquinconazole } & \multicolumn{2}{|c|}{ TS padrão com fluquinconazole } & \multicolumn{2}{|c|}{ TS padrão sem fluquinconazole } & \multicolumn{2}{|c|}{ TS padrão com fluquinconazole } \\
\hline & $1994 \mathrm{~b}$ & A & $2131 \mathrm{~b}$ & A & $1848 \mathrm{~b}$ & A & $2141 \mathrm{~b}$ & A \\
\hline $\begin{array}{l}\text { 2.Pyraclostrobin }+ \\
\text { epoxiconazole } \\
\end{array}$ & $3102 \mathrm{a}$ & A & $3363 \mathrm{a}$ & A & $4222 \mathrm{a}$ & A & $4647 \mathrm{a}$ & A \\
\hline $\begin{array}{l}\text { 3. Trifloxystrobin }+ \\
\text { ciproconazole }+ \text { Aureo }\end{array}$ & $3174 \mathrm{a}$ & A & 3276 a & A & 4341 a & A & $4464 \mathrm{a}$ & A \\
\hline $\begin{array}{l}\text { 4. Azoxystrobin }+ \\
\text { ciproconazole }+ \text { Nimbus }\end{array}$ & 3217 a & A & 3285 a & A & 4572 a & A & $4509 \mathrm{a}$ & A \\
\hline $\begin{array}{l}\text { 5. Pyraclostrobin }+ \\
\text { propiconazole }+ \text { Áureo) } \\
+ \text { tebuconazole }\end{array}$ & 3256 a & A & $3405 \mathrm{a}$ & A & 4490 a & A & $4677 \mathrm{a}$ & A \\
\hline
\end{tabular}

Médias seguidas de mesma letra minúscula na coluna e maiúscula na linha não diferem significativamente entre si (Duncan, 5\%)

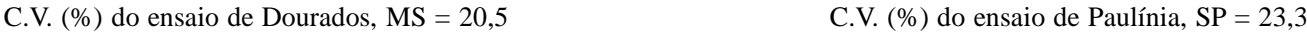

DAP = dias após o plantio

TS padrão $=$ tratamento de sementes padrão $=$ carbendazim + thiram + imidacloprid

rendimento de grãos da cultura.

Resultados obtidos por Togni et al. (19), Miguel-Wruck et al. (16), Menten et al. (15), Furlan \& Scherb (5), Iamamoto et al. (11) e Marolli et al. (12) evidenciaram benefícios do tratamento de sementes de soja com o fungicida fluquinconazole no manejo da ferrugem asiática, sempre associado ao tratamento da parte aérea, o que resultou na redução da velocidade da doença quando comparada com aquela observada em plantas cujas sementes não receberam este tratamento, contribuindo, assim, para maximizar o controle dessa enfermidade. Por outro lado, resultados obtidos por Godoy \& Henning (8) demonstraram que o tratamento de sementes com fluquinconazole não atrasou a evolução da ferrugem da soja e não apresentou diferença significativa com o tratamento sem fluquinconazole, não apresentando benefício no manejo desta doença. Estes autores verificaram ainda não haver interação significativa entre o tratamento de sementes com fluquinconazole e os tratamentos de mistura de fungicidas aplicados na parte aérea da soja.

As vantagens do uso do tratamento de sementes de soja para o controle de Phakopsora pachyrhizi devem ser avaliadas ao longo do tempo em diversas situações de pressão do inóculo, clima, altitude, espaçamento, nutrição, épocas de semeadura e em diferentes variedades de soja, para conhecer melhor a importância e uso desta nova ferramenta para o controle da ferrugem asiática e outras doenças de parte aérea na cultura da soja.

\section{REFERÊNCIAS BIBLIOGRÁFICAS}

1. Andrade, P.J.M.; Andrade, D.F.A.A. Ferrugem asiática: uma ameaça à sojicultura brasileira. Dourados MS. Embrapa Agropecuária Oeste, Circular Técnica, 11. 2002.

2. Azevedo, L.A.S. Tratamento de sementes com fungicidas visando o controle der patógenos da parte aérea. In: 4. Simpósio Brasileiro de Patologia de Sementes. Campinas SP. Fundação Cargill. pp.83-91. 1996.

3. Carvalho Júnior; A.A, Figueiredo, M.B A verdadeira identidade da ferrugem da soja no Brasil. Summa Phytopathologica 26:197200. 2000 .

4. Consórcio Antiferrugem: Tabela de custo. Disponível em: < h t t p :// www. consorcioantiferrugem.net/
?Conhe\%E7a_a\%26nbsp\%3Bferrugem\%26nbsp\%3B:Tabela_de_custo.> Acesso em 24 mar. 2008.

5. Furlan, S.H.; Scherb, C.T. Tratamento de sementes de soja com fluquinconazole associado a pulverização de fungicidas visando o controle da ferrugem asiática e da mancha parda. In: 29. Reunião de Pesquisa de Soja da Região Central do Brasil. Londrina PR. Embrapa Soja, Documentos 287. pp. 73-76. 2007.

6. Furlan, S.H.; Goulart, A.C.P. Soja - Evolução do tratamento de sementes: o caso da ferrugem asiática. Revista Plantio Direto 101:24-29. 2008.

7. Godoy, C.V.; Koga, L.J.; Canteri, M.G. Diagrammatic scale for assessment of soybean rust severity. Fitopatologia Brasileira 31:63-68. 2006

8. Godoy, C. V.; Henning, A. A. Tratamento de semente e aplicação foliar de fungicidas para o controle da ferrugem-da-soja. Pesquisa Agropecuária Brasileira, v. 43, n.10, p.1297-1302, out. 2008.

9. Goulart, A.C.P.; Melo Filho; G.A. Quanto custa tratar as sementes de soja, milho e algodão com fungicidas? Dourados MS. Embrapa Agropecuária Oeste, Documentos, 11. 2000.

10. Henning, A.A.; Krzyzanowski, F.C.; França Neto, J.B.; Yorinori, J.T. Tratamento de sementes de soja com fungicidas. Londrina PR. EMBRAPA-CNPSo, Comunicado Técnico, 49. 1991.

11. Iamamoto, M.M.; Silveira, C.; Alberton, M. Efeito de fluquinconazole no tratamento de sementes na ferrugem asiática da soja Phakopsora pachyrhizi. In: 31. Congresso Paulista de Fitopatologia. Campinas SP. Instituto Biológico. Resumo 298. 2008.

12. Marolli, M.K.; Kobayasti L.; Cassetari Neto ,D. Tratamento de sementes e pulverizações foliares associadas no controle da ferrugem asiática da soja nas fases iniciais de desenvolvimento da cultura. In: 31. Congresso Paulista de Fitopatologia. Campinas SP. Instituto Biológico. Resumo 314. 2008.

13. Martinelli, J.A. Controle de ferrugem da folha (Puccinia recôndita) do trigo (Triticum aestivum) pelo tratamento de sementes e sua conseqüência sobre o tratamento aéreo convencional. Fitopatologia Brasileira 20:304. Suplemento. Ref. 156. 1995.

14. Menegon, A.P.; Forcelini, C.A.; Fernandes, J.M.C. Expansão de lesão da mancha-reticular da cevada e sua interação com o tratamento de sementes. Fitopatologia Brasileira 30:139-142. 2005.

15. Menten, J.O.M.; Togni, D.A.J.; Calaça, H.A.; Bertucci-Ramos, P.H.; Veiga, J.S.; Suzuki, M. Aporte del tratamiento de semillas em el manejo de la roya asiática de la soya. In: XIV Congresso Latinoamericano y del Caribe de Fitopatologia, México. pp.61. 2007.

16. Miguel-Wruck, D.S.; Zito, R.K.; Paes, J.M.V. Eficiência de fluquinconazole via tratamento de sementes no controle da ferru- 
gem asiática da soja. In: 29. Reunião de Pesquisa de Soja da Região Central do Brasil. Londrina PR. Embrapa Soja, Documentos 287. pp. 70-72. 2007.

17. Sinclair, J.B.; Backman, P.A. Infectious diseases: rust. In: Sinclair, J.B.; Backman, P.A. (Eds.) Compendium of soybean diseases. 3. ed. St. Paul. APS Press. pp. 24-27. 1989.

18. Tecnologias de produção de soja - Região Central do Brasil 2008. Londrina PR. Embrapa Soja: Planaltina: Embrapa Cerrados: Campinas: Embrapa Agropecuária Oeste, 2008. 280p. (Embrapa Soja. Sistemas de Produção, 12).

19. Togni, D.A.J.; Menten, J.O.M.; Stasievski, A. Efeito do trata- mento de sementes + aplicação de fungicidas no manejo da ferrugem asiática da soja. In: 29. Reunião de Pesquisa de Soja da Região Central do Brasil. Londrina PR. Embrapa Soja, Documentos 287. p.66-69. 2007.

20. Yorinori, J.T.; Nunes Junior, J.; Lazzarotto, J.J. Ferrugem "asiática" da soja no Brasil: evolução, importância econômica e controle. Londrina PR. Embrapa Soja, Documentos, 247. 2004

21. Yorinori, J.T.; Paiva, W.M.; Frederic, R.D.; Costamilan, L.M.; Bertagnolli, P.F. Epidemia da ferrugem da soja (Phakopsora pachyrhizi) no Brasil e no Paraguai, em 2001 e 2002. Fitopatologia Brasileira 27:S178-179. Suplemento. 2002. 